\title{
PULMONARY HYPERTENSION WITH SPECIAL REFERENCE TO THE VASOCONSTRICTIVE FACTOR*
}

\author{
BY \\ PAUL WOOD \\ From the Institute of Cardiology, National Heart Hospital, and the Brompton Hospital \\ Received July 2, 1958
}

The normal pulmonary blood pressure in a series of 60 normal controls studied at the Institute of Cardiology and at the Brompton hospital was $16 / 7 \mathrm{~mm}$. $\mathrm{Hg}$ with reference to the sternal angle, the mean being $11 \mathrm{~mm}$. and the range $8 / 2-28 / 14 \mathrm{~mm}$. The mean cardiac output was 8 litres a minute, and the common range 5.5 to 10.5 litres a minute. The left atrial pressure averaged 2 to $3 \mathrm{~mm}$. $\mathrm{Hg}$.

The pulmonary vascular resistance, which in simple units is the pulmonary artery pressure minus the left atrial pressure in $\mathrm{mm}$. Hg divided by the pulmonary blood flow in litres a minute, was therefore about 1 unit or 80 dynes sec. $/ \mathrm{cm} .^{-5}$.

Definition of Pulmonary Hypertension. Pulmonary hypertension literally implies a pulmonary blood pressure above $30 / 15 \mathrm{~mm}$. which is the upper limit of the normal range. In practice serious pulmonary hypertension usually means a pressure at or around systemic level, but rarely in excess of $150 \mathrm{~mm}$.

\section{Classification}

There are five basic types of pulmonary hypertension as shown in the classification below, and it may help to add a sixth (polygenic), to describe cases of mixed ætiology.

\begin{tabular}{l|l}
\hline \multicolumn{1}{c|}{ Type } & \multicolumn{1}{c}{ Definition } \\
\hline $\begin{array}{l}\text { Passive } \\
\text { Hyperkinetic } \\
\text { Obstructive } \\
\text { Obliterative } \\
\text { Vasoconstrictive } \\
\text { Polygenic }\end{array}$ & $\begin{array}{l}\text { Raised pulmonary venous pressure } \\
\text { Increased pulmonary blood flow } \\
\text { Pulmonary embolism or thrombosis } \\
\text { Reduction of pulmonary vascular capacity } \\
\text { Functional vasoconstrictive reaction } \\
\text { Arising in more than two of the above ways }\end{array}$ \\
\hline
\end{tabular}

Passive pulmonary hypertension is caused by any condition that elevates the pulmonary venous pressure, e.g. left ventricular failure, mitral valve disease, myxoma of the left atrium, cor triatriatum, multiple pulmonary venous thrombosis, constrictive pericarditis, and tense pericardial effusion.

Hyperkinetic pulmonary hypertension due to increased flow may occur in patent ductus, aortopulmonary septal defect, perforation of an aortic sinus into the pulmonary artery or right ventricle or right atrium, ventricular septal defect, perforated ventricular septum, atrial septal defect, and partial anomalous pulmonary venous drainage into the right atrium. Associated with central cyanosis it may occur in transposition of the great vessels, persistent truncus, pulmonary atresia

* The George Fahr Lecture, delivered at the University of Minnesota, U.S.A. on March 18, 1958. This lecture is a modification of the hitherto unpublished Litchfield lecture delivered to the University of Oxford on March 6, 1957. 
with a large broncho-pulmonary shunt, single ventricle, single atrium, and total anomalous pulmonary venous drainage directly or indirectly into the right atrium. Acquired hyperkinetic circulatory states do not as a rule cause a sufficiently high cardiac output to raise the pulmonary blood pressure.

Obstructive pulmonary hypertension results classically from massive or multiple embolism or thrombosis, and may be acute, subacute, or chronic. Surgical ligation of a main pulmonary artery in cases of pneumonectomy provides an important obstructive component to pulmonary hypertension initiated by disease in the remaining lung. Other contributory causes include stenosis of one or more main branches of the pulmonary artery, absence of a main branch of a pulmonary artery, and compression of a main pulmonary artery from a space filling lesion such as a tumour, cyst, or aneurysm.

Obliterative pulmonary hypertension may occur at capillary, arteriolar, or arterial level. Capillary obliteration may accompany emphysema and interstitial fibrosis; occlusive disease of the arterioles and muscular arteries is usually caused by great thickening of the intima-endarteritis fibrosa. This group includes all forms of cor pulmonale in which the resistance is permanently high, schistosomiasis, disseminated lupus, periarteritis, and perhaps primary pulmonary hypertension. It may also complicate all other forms of pulmonary hypertension of sufficient duration, just as organic vascular disease complicates essential hypertension in the systemic circulation.

Vasoconstrictive pulmonary hypertension occurs in response to acute alveolar hypoxia, as first demonstrated by Liljestrand (1948). In practice this is seen chiefly when acute respiratory infections or "bronchospasm" complicate cases of chronic lung disease, and it may play an important role in neo-natal asphyxia. Certain drugs, such as phenylephrine, may also cause pulmonary vasoconstriction. Just what part vasoconstriction plays in other forms of pulmonary hypertension will be discussed later.

Polygenic pulmonary hypertension is best illustrated by cor pulmonale, when hyperkinetic, obliterative, and hypoxic vasoconstrictive factors may all operate together. Another good example is when hyperkinetic pulmonary hypertension is suddenly complicated by massive thrombosis of one of the main pulmonary arteries. But it is becoming increasingly clear that almost any form of pulmonary hypertension may become polygenic in one way or another, a point that will be elaborated subsequently.

\section{Reactive Pulmonary Hypertension}

This term may be used with advantage when it is desirable not to beg the question of æatiology. It is particularly applicable to the extreme pulmonary hypertension that may complicate cases of mitral stenosis or cases with potentially large left-to-right shunts. The word implies and is intended to imply that the high pulmonary vascular resistance in these cases is a reaction of some sort to passive or hyperkinetic pulmonary hypertension. It has been omitted from the classification because its mechanism is likely to be identified with one or more of those listed. Reactive pulmonary hypertension may well aggravate obstructive and obliterative pulmonary hypertension as well.

The most fundamental problem concerning the pulmonary circulation at the present time is the nature of this reactive pulmonary hypertension. It must be due either to the development of thrombo-obstructive or obliterative vascular disease involving the muscular arteries and/or the arterioles, or to active pulmonary vasoconstriction.

The chief object of this paper is to consider the importance of the vasoconstrictive factor.

\section{Passive (and Reactive) Pulmonary Hypertension}

Passive pulmonary hypertension implies a left atrial pressure of at least $20 \mathrm{~mm}$. $\mathrm{Hg}$; if the normal mean P.A.-L.A. pressure gradient of about $10 \mathrm{~mm}$. is preserved, this will result in a pulmonary artery pressure of about $40 / 20 \mathrm{~mm}$. This is the usual situation in mitral stenosis at rest. On effort, 
the left atrial pressure rises sharply and may easily reach $50 \mathrm{~mm}$. Hg (Fig. 1). If the cardiac output doubles and the resistance remains unchanged, the pulmonary artery pressure would then measure about $100 / 50 \mathrm{~mm}$. That pulmonary œdema does not necessarily occur when the left atrial pressure exceeds the osmotic pressure of the plasma has been attributed to the development of an interstitial barrier between the pulmonary capillaries and the alveoli, as described by Hayward (1955). About two-thirds of all cases of critical mitral stenosis have uncomplicated passive pulmonary hypertension of this kind. They may suffer from recurrent hæmoptysis, attacks of acute pulmonary odema, and winter bronchitis due to the high pulmonary and bronchial venous pressure, and from paroxysmal nocturnal dyspnœa, orthopnœa, and severe breathlessness on effort due to chronic interstitial œdema of the lung.

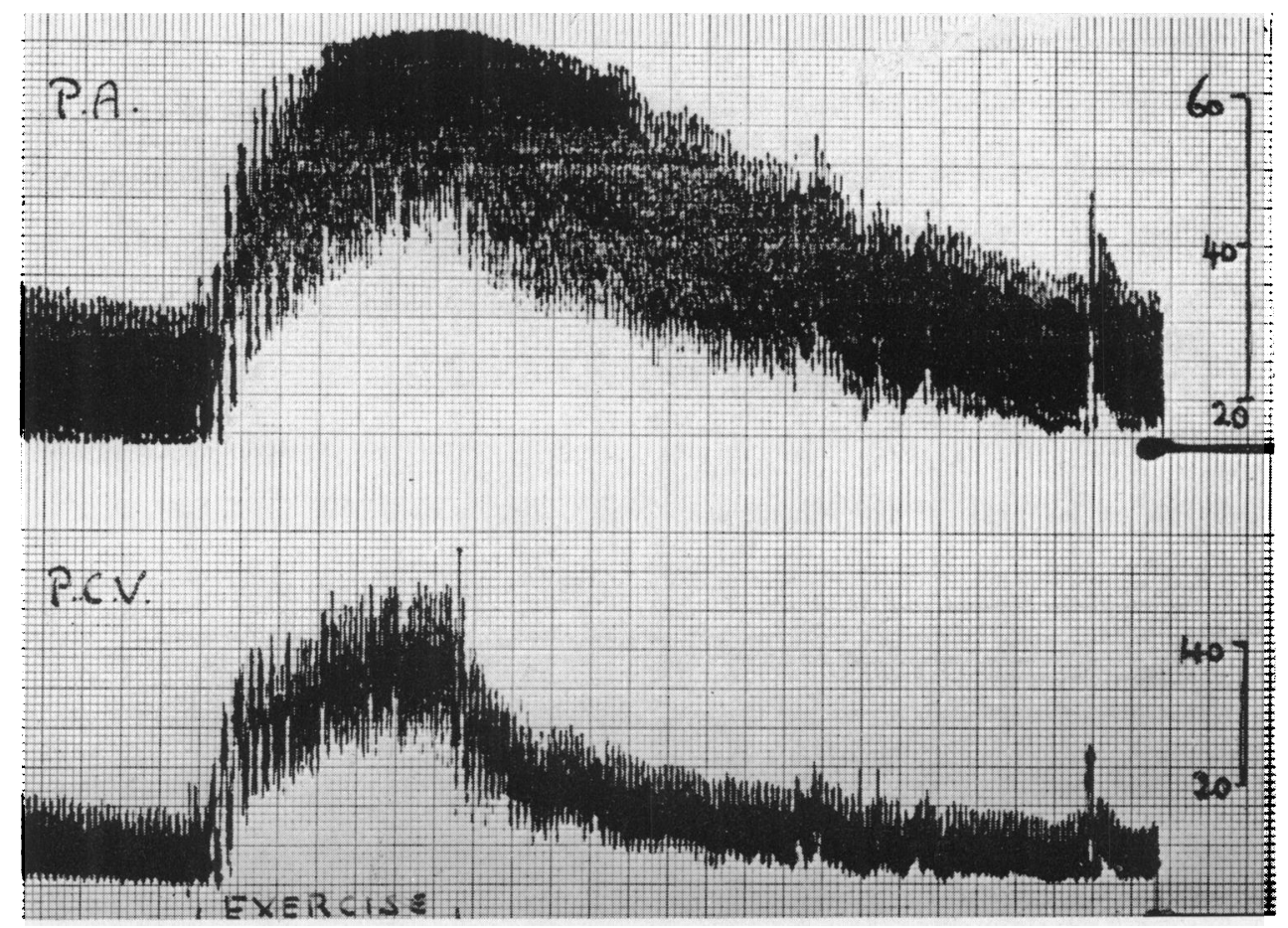

FIG. 1.-Left atrial (P.C.V.) and pulmonary arterial pressure in a case of mitral stenosis at rest and on exercise, showing passive pulmonary hypertension.

Reactive Pulmonary Hypertension in Mitral Stenosis. In about one-third of cases of critical mitral stenosis, however, the pulmonary artery pressure is raised disproportionately to the left atrial pressure, owing to an increase in the pulmonary vascular resistance. Thus in a series of 500 cases in which the mitral orifice measured between $5 \times 3 \mathrm{~mm}$. and $15 \times 7.5 \mathrm{~mm}$., the resistance was 6 to 10 units in 16 per cent and over 10 units in 12 per cent. The 60 patients with resistances over 10 units were regarded as having reactive pulmonary hypertension of the highest order and were selected for further study.

The problem was what caused the reaction? Was it the slow development of obliterative pulmonary vascular disease in response to prolonged passive pulmonary hypertension, or was it some more vital process such as reactive pulmonary vasoconstriction?

Had obliterative pulmonary vascular disease been responsible for the reaction one would have expected it chiefly in the older patients; and since a high pulmonary vascular resistance diminishes pulmonary venous congestion, one would have expected these patients to give a history of earlier 
hæmoptysis, pulmonary œdema, paroxysmal cardiac dyspnœa, and orthopnœa followed by relief of these symptoms and their replacement by fatigue, hepatic pain, and œdema. In fact, however, the average age of these patients was precisely the same as the average age of those with uncomplicated passive pulmonary hypertension (39), and 80 per cent of them gave no history of pulmonary congestive symtoms at any time. A number of dramatic cases, presenting very like primary pulmonary hypertension, occurred in young women between the ages of 20 and 30 . It seemed more likely, therefore, that the high resistance represented an active physiological process, and was not a late complication of passive pulmonary hypertension. The remarkable fall in resistance that followed technically successful valvotomy seemed to confirm this idea, for obliterative pulmonary vascular disease would not have been expected to behave in this way.

Demonstration of a Vasoconstrictive Factor. With the idea that the reaction might be vasoconstrictive, I decided to inject acetylcholine into the pulmonary artery thinking that it might prove a selective pulmonary vasodilator, and that a suitable dose would be destroyed by the time it reached the systemic circulation. In fact, a dose of $1 \mathrm{mg}$. injected rapidly into the pulmonary artery in a case of primary pulmonary hypertension had precisely the affect we desired: the pulmonary blood pressure fell and the systemic blood pressure rose (owing to the increase of cardiac output resulting from the fall in resistance). Since then (April, 1955) we have given acetylcholine to 16 cases of mitral stenosis, see Table I. In 8 the resistance was extreme (12 to 26 units), in 4 it was high ( 6 to 10 units) and in 4 it was only slightly raised ( 2.5 to 5 units). The technique has been described fully elsewhere (Wood et al., 1957).

TABLE I

Summary of Results of ACETylCholine Test

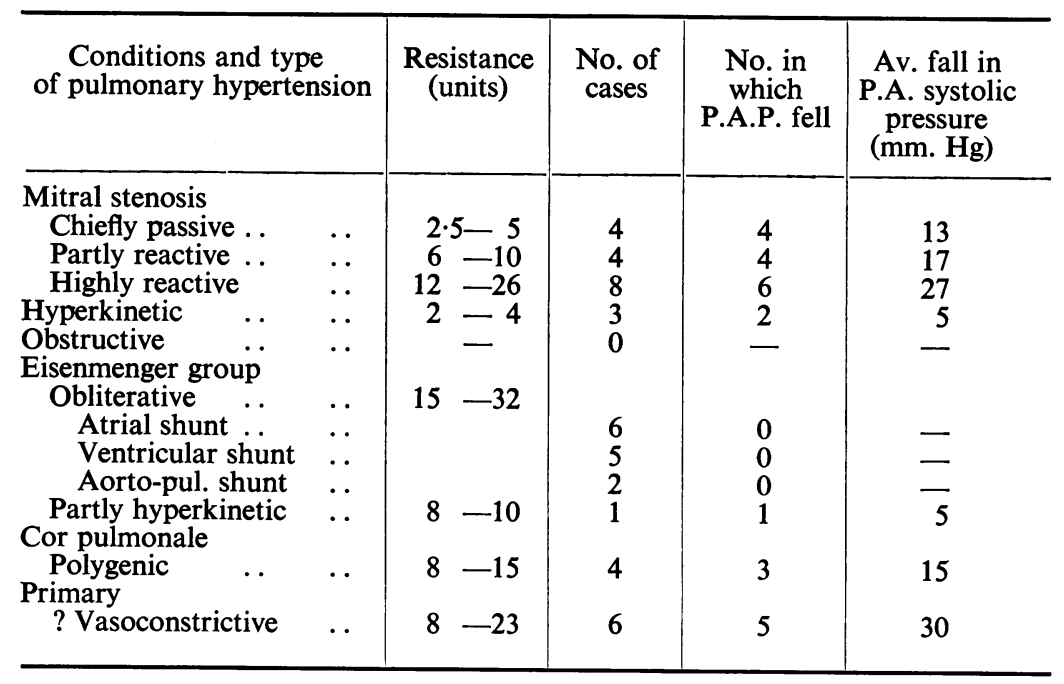

The results were fairly uniform. The pulmonary blood pressure and pulmonary vascular resistance fell appreciably, and the left atrial pressure rose (Fig. 2); the cardiac output, blood pressure, and pulse rate remained much the same. The effect was greatest in those with the highest resistances, except in two cases that did not respond at all. The average fall in resistance was from 9 to 5 units approximately.

These observations demonstrate the existence of a powerful vasoconstrictive factor in cases of reactive pulmonary hypertension secondary to mitral stenosis. The two cases that did not respond to acetylcholine were very advanced and may well have had gross secondary obliterative changes and late thrombo-obstructive lesions. 


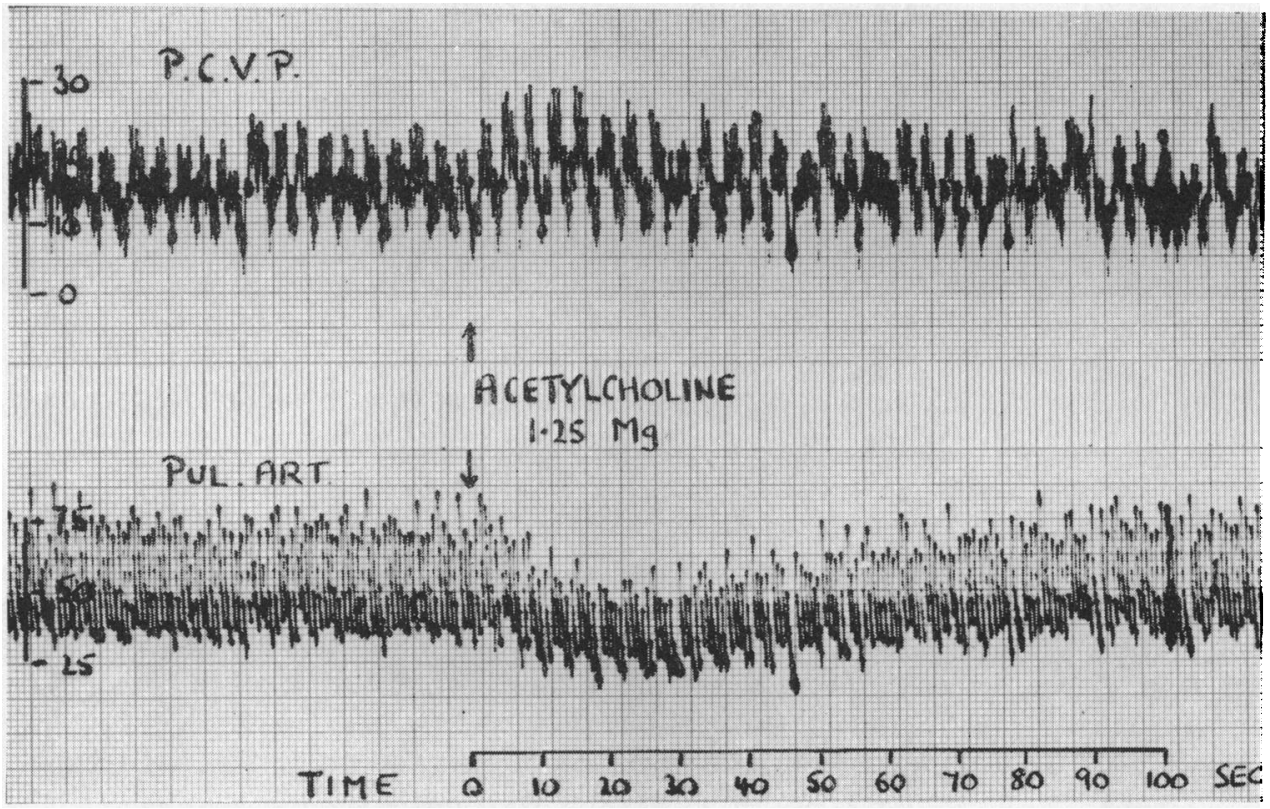

FIG. 2.-Effect of acetylcholine on the pulmonary arterial and left atrial (P.C.V.) pressure in a case of mitral stenosis with a pulmonary vascular resistance of 14 units.

\section{Hyperkinetic (and Reactive) Pulmonary Hypertension}

When the pulmonary blood flow increases, the resistance falls and so prevents a rise of pressure. This holds good for normal subjects with flows up to about 16 litres a minute, which is double normal, and for resistances down to 0.5 units, which is half normal (Hickham and Cargill, 1947; Cournand, 1950). At about this level maximum pulmonary vascular capacity is reached, and any further increase of flow causes a rise of pressure. This is hyperkinetic pulmonary hypertension. It is pointed out, however, that with a flow of 24 litres a minute and a pulmonary vascular resistance of 0.5 units, the mean pulmonary blood pressure is only $12 \mathrm{~mm}$. Hg with reference to the sternal angle. Flows and pressures of this order are common enough in atrial septal defect and would hardly be ranked as pulmonary hypertension. On the other hand if the resistance fails to fall and is in the upper range of normal, say 2 units, then a pulmonary blood flow of 24 litres a minute would result in a mean pulmonary artery pressure of $48 \mathrm{~mm}$. $\mathrm{Hg}$, which would certainly be regarded as pulmonary hypertension. Since pulmonary blood flows in excess of 30 litres a minute are rarely if ever encountered, being beyond the working capacity of the heart, it follows that hyperkinetic pulmonary hypertension implies a high normal pulmonary vascular resistance or at least failure of the resistance to fall in response to increased flow. In practice the definition of the term is usually extended to cover cases of pulmonary hypertension associated with a high pulmonary blood flow and a resistance not exceeding 4 units. Hyperkinetic pulmonary hypertension so defined often reaches systemic level.

Reactive Pulmonary Hypertension in Potentially Hyperkinetic Cases. Of particular interest are those cases with a large communication between the two circulations in which a high pulmonary blood flow is prevented by an extreme pulmonary vascular resistance more or less at systemic level (12 to 30 units). I have called this the Eisenmenger reaction, or Eisenmenger's syndrome, for it was pure chance that Eisenmenger's case happened to have a ventricular septal defect, what he described clinically being compatible with a reversed shunt at any level. It is now known that the only important factor that determines the direction of a shunt through a patent ductus or ventricular septal defect is the relationship between the systemic and pulmonary vascular resistances. The 
situation in atrial septal defect is more or less similar, but there are at least seven other causes of reversed inter-atrial shunt. The problem that concerns us here is the nature of the high pulmonary vascular resistance in the Eisenmenger syndrome.

The chief hypotheses that have been advanced to explain the high resistance in these cases include congenital deficiency of the media of the muscular arteries with over-compensating endarteritis fibrosa of the intima (Gilmour and Evans, 1946), persistence of the fœtal type of pulmonary circulation with thick muscular arteries designed to maintain a high pressure (Civin and Edwards, 1950, 1951), the gradual development of obliterative pulmonary vascular disease as a complication of pulmonary plethora (the most widespread theory), and a vasoconstrictive reaction that may develop in response to severe hyperkinetic pulmonary hypertension in infancy (Wood, 1956). While it is impossible to discuss these theories adequately, evidence is offered that favours a polygenic mechanism.

\section{Clinical Evidence}

(1) In my own series the Eisenmenger reaction occurred in 16 per cent of 180 cases of patent ductus, in 25 per cent of 164 cases of ventricular septal defect, and in 8 per cent of 332 cases of atrial septal defect. As will be seen presently, this remarkable difference in frequency is attributed to the size of the defect, the length of the period in the cardiac cycle during which the shunt operates, and the swiftness with which an increased pulmonary blood flow tends to develop after birth.

(2) The size of the communication between the two circulations is very revealing. In uncomplicated patent ductus, ventricular septal defect, and atrial septal defect, it is usually 1 to $7.5 \mathrm{~mm}$., 1 to $15 \mathrm{~mm}$., and 3 to $8 \mathrm{~cm}$. in diameter respectively. Necropsies of well-investigated cases of the Eisenmenger syndrome are rare, but by the courtesy of my colleagues I now have details of 30 such cases, 10 in each group: in these the ducts measured 7.5 to $15 \mathrm{~mm}$. in diameter, the ventricular septal defects 1.5 to $3 \mathrm{~cm}$., and the atrial septal defects 3 to $4 \mathrm{~cm}$. across. The smallest ducts had virtually no length. It will be appreciated that the size of the communication is vital at aortopulmonary or ventricular level, but not at atrial level. It will also be observed that ventricular septal defects had twice the diameter of the ducts; this may be explained by the fact that a shunt through a patent ductus is potentially continuous, whereas through a ventricular septal defect it is mainly confined to systole. These facts leave no room for doubt that the Eisenmenger reaction is directly related to the potential magnitude of the pulmonary blood flow. The suggestion that the fault lies with some associated congenital anomaly of the muscular pulmonary arteries is therefore untenable, for one could hardly expect this fault to be associated only with these large defects. The anatomical data also deny that an overriding aorta has anything to do with the Eisenmenger reaction.

(3) In 103 cases of Eisenmenger's syndrome in which the level of the shunt was established physiologically with a high probability of accuracy, 28 were aorto-pulmonary, 42 ventricular, and 33 atrial (including 9 cases believed to have an ostium primum). The life histories of these cases indicated that reactive pulmonary hypertension with reversed or bi-directional shunt had been present since birth or early infancy in at least 80 per cent of those with patent ductus, and 90 per cent of those with ventricular septal defect, whereas it had been so present in a maximum of only 10 per cent of those with atrial septal defect. Thus if obliterative vascular disease is responsible for reactive pulmonary hypertension in cases of patent ductus and ventricular septal defect, it must develop remarkably quickly. Moreover, since torrential flows in atrial septal defect continue for several decades before being complicated by a high resistance (if ever), rapidly developing obliterative vascular disease of the kind postulated must be attributed to high pressure, not to increased flow. It follows that the high pressure must precede the intimal thickening, which means that obliterative pulmonary vascular disease cannot be initially responsible for reactive pulmonary hypertension in the Eisenmenger syndrome.

(4) The remarkable difference in the behaviour of cases with atrial septal defect demands some comment. In the first place it must be pointed out that the remark applies to the ordinary secundum defect, much less so to the ostium primum, which may behave like a ventricular septal defect 
in respect of the Eisenmenger reaction. Thus of the 9 ostium primum cases with reactive pulmonary hypertension in the present series, all but one dated from birth or early infancy. It is suggested that a secundum type of defect may not function as such for some weeks or months after birth, because the filling resistance of the hypertrophied right ventricle should not be dissimilar to that of the left at that time, an idea expressed independently by Edwards (1957). If the right ventricle takes longer to involute than the muscular pulmonary arteries of the fotus, then the pulmonary vascular resistance would fall to normal before an appreciable left-to-right shunt tended to keep the pressure up. As stated previously, once the resistance is normal it is extremely difficult for high flows to cause significant pulmonary hypertension.

\section{Pathological Evidence}

It is always dangerous to argue physiologically from anatomical data. A prime illustration of this axiom relating to the present subject was the belief that an overriding aorta explained Eisenmenger's complex. Nevertheless, there are certain pathological findings that may have great significance, and these must be mentioned briefly. The first of these is the hypertrophied media of the muscular arteries of the fœtus. Very similar appearances during the first two years of life in cases of Eisenmenger's complex led Edwards (1950) to postulate that it was the persistence of the fœtal type of pulmonary circulation that maintained the high pulmonary vascular resistance in the Eisenmenger syndrome and so prevented a left-to-right shunt of a magnitude that endangered life. The rapid involution of these vessels after birth, parallel with a fall in pulmonary vascular resistance, suggests that in the fœtus they are in a state of active vasoconstriction.

The second pathological finding of great significance in the Eisenmenger syndrome is the absence of obliterative thickening of the intima during the first two years of life (Edwards, 1957). This indicates that "endarteritis fibrosa" is a result rather than a cause of the Eisenmenger syndrome, and is an anatomical reaction to high pressure not to increased flow, because the latter has already been prevented in these cases.

The third important finding is that the thickened media of the muscular arteries in established cases of Eisenmenger's syndrome represent larger arteries in a state of contraction rather than smaller arteries with greatly thickened coats (Short, 1957).

Finally, the high incidence of thrombo-obstructive lesions in later life cannot be ignored.

The most likely interpretation of these pathological data is that something prevents the thick muscular arteries of the fotus from involuting after birth, and maintains them in a state of active vasoconstriction. The agent responsible cannot be an increased pulmonary blood flow, because that is prevented by the reaction under discussion. What is more likely than that it results from pulmonary hypertension itself? With a large defect at aorto-pulmonary or ventricular level any fall in resistance would at once be met by an increase in pulmonary flow which would maintain the pulmonary blood pressure at systemic level. Only a very small hyperkinetic factor is required to maintain the pulmonary blood pressure at systemic level in the presence of a resistance of say 10 units, which is well below that in the fotus. Reactive obliterative intimal thickening seems to develop gradually over the years, and may well slowly replace vasoconstriction as the chief means of maintaining the high resistance. Thrombo-obstructive lesions occur later still.

\section{Physiological Observations}

In an attempt to determine what part vaso-constriction might be playing in the Eisenmenger syndrome, acetyl-choline was given to 13 cases with resistances ranging between 15 and 32 units. The communication between the two circulations was atrial in 6 , ventricular in 5 , and aorto-pulmonary in 2 . The pulmonary blood pressure did not fall primarily in a single instance (Fig. 3 ), even with a dose of $2 \mathrm{mg}$. It seemed possible, however, that a fall in resistance might be compensated for by increased flow without any alteration of pressure; accordingly, the arterial oxygen saturation was measured simultaneously, on the chance that it might rise, but in no instance was any such rise observed (Fig. 4). Instead, however, in some cases there was a fall (Fig. 5). This 
suggested the possibility of a paradoxical response, and shortly afterwards we obtained an actual rise of pulmonary artery pressure in one case which seemed to confirm the possibility (Fig. 6). Then came a report from Adams et al. (1957) that acetylcholine caused pulmonary vasoconstriction in newborn babes. This seemed to clinch the matter, and in conjunction with our findings appeared to confirm Edwards' idea that the pulmonary vessels in Eisenmenger's syndrome remained fotal in character.

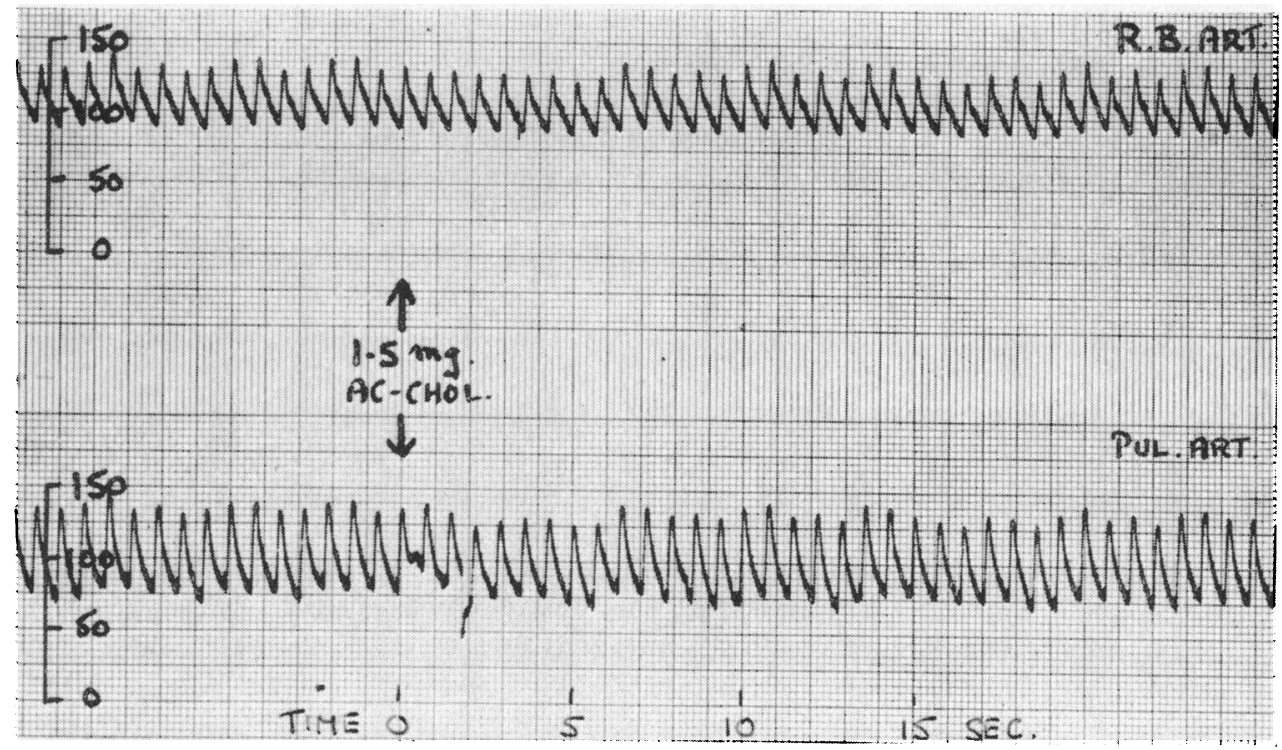

FIG. 3.-Brachial and pulmonary arterial pressure in a case of Eisenmenger's complex (with necropsy proof): acetylcholine fails to lower the pulmonary vascular resistance.

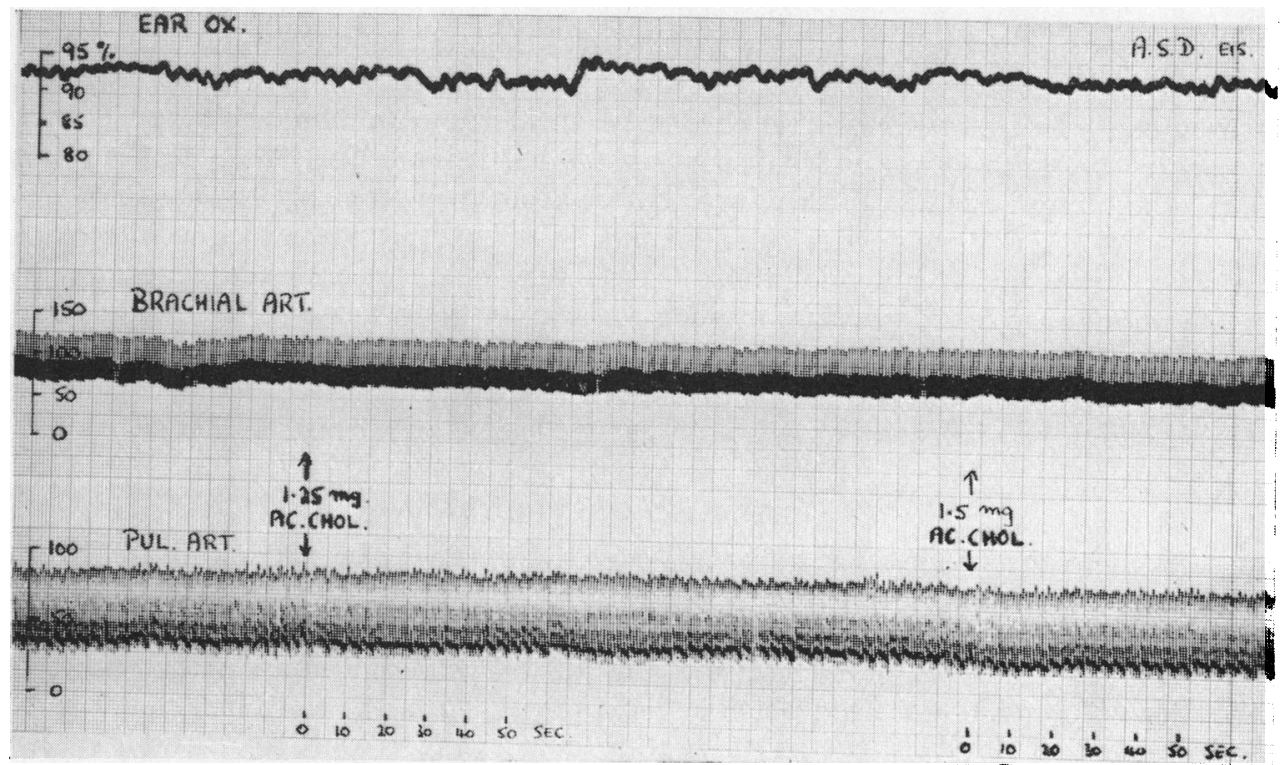

FIG. 4.-Acetylcholine also fails to raise the arterial oxygen saturation in a case of atrial septal defect with the Eisenmenger reaction. 
There were two further surprises in store, however. First we found that acetylcholine lowered the arterial oxygen saturation sharply, as well as the pulmonary artery pressure, in a case of cor pulmonale, suggesting that it may open up physiologically closed vascular pathways through unventilated lung, and that this might occur to a lesser extent in any kind of patient lying quietly on a catheter table, particularly when premedicated with barbiturate. Both observation and expectation have been amply confirmed since. This means that a fall in arterial oxygen saturation

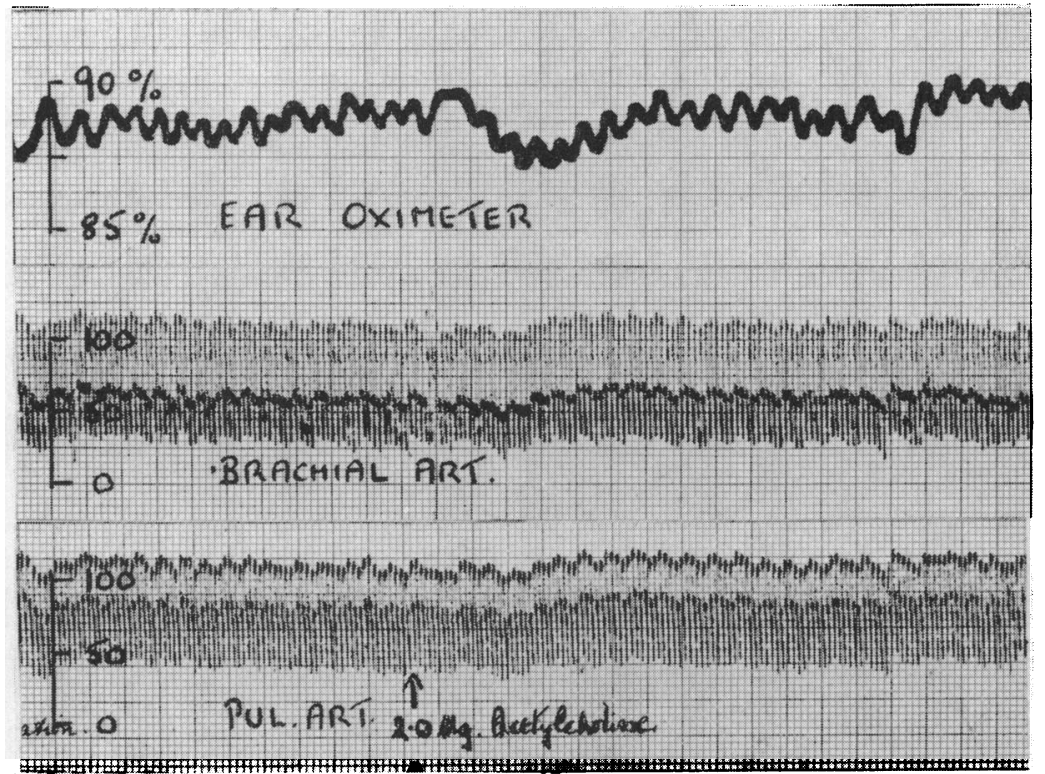

FIG. 5.-Acetylcholine injected into the pulmonary artery may lower the arterial oxygen saturation in some cases of Eisenmenger's syndrome.

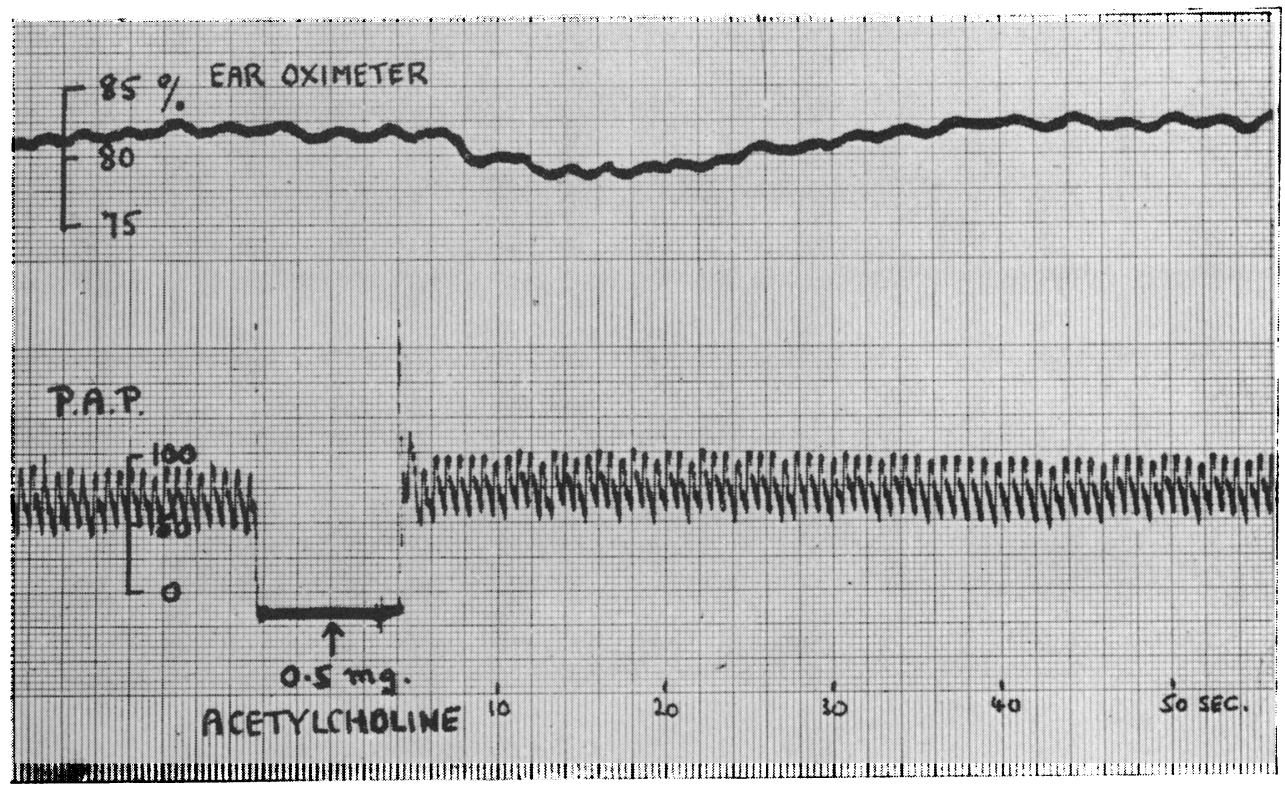

FIG. 6.-Rise of pulmonary artery pressure and fall of arterial oxygen saturation after injecting acetylcholine in a case of persistent ostium primum with the Eisenmenger reaction. 
following an injection of acetyl-choline in cases of Eisenmenger's syndrome cannot be taken as evidence of an increased right-to-left shunt secondary to pulmonary vasoconstriction.

I then wrote to Dr. Geoffrey Dawes and asked him if he would be kind enough to check the effect of acetylcholine on the fetal pulmonary circulation in animals, and he has since told me that in his first few experiments he obtained a sharp drop in pulmonary blood pressure when using a dose equivalent to ours. At the present time, therefore, the point remains equivocal.

The fact is established, however, that acetylcholine fails to lower the pulmonary vascular resistance in cases of the Eisenmenger syndrome in adults and children over 5 years old. Whether this is due to secondary obliterative pulmonary vascular disease or to an unusual physiological response remains to be seen.

It is possible to go further in one respect, however. If in the Eisenmenger syndrome one of the pulmonary arteries is stenosed, so that the pressure beyond the stricture is appreciably below systemic level, then the response to acetyl-choline delivered to that pulmonary artery is normal, the pressure falling sharply (Fig. 7). This helps to dispose of the idea that the fault in the peripheral pulmonary arteries in Eisenmenger's syndrome is congenital.

A

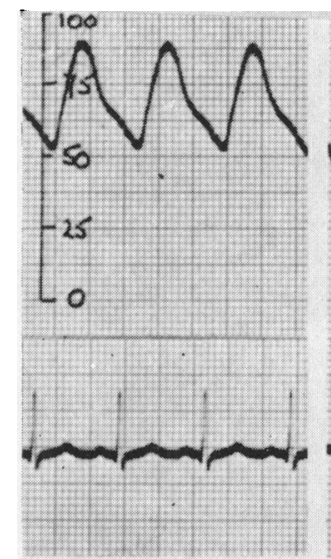

AORTA

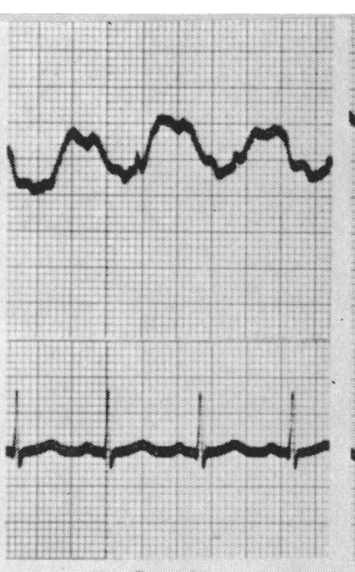

R.P.A

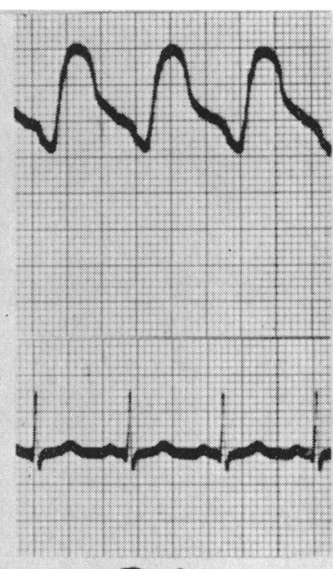

P.A

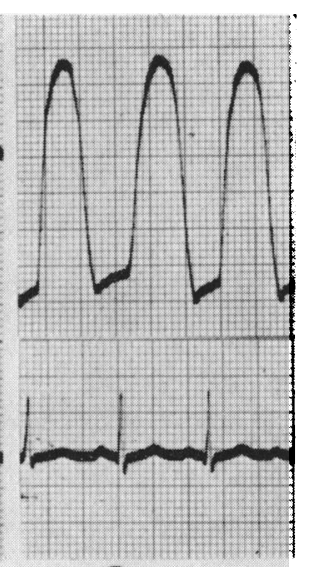

R.V.

\section{AORTA}

$\Gamma^{100}$

Hั4

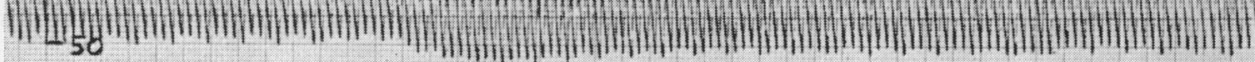

B

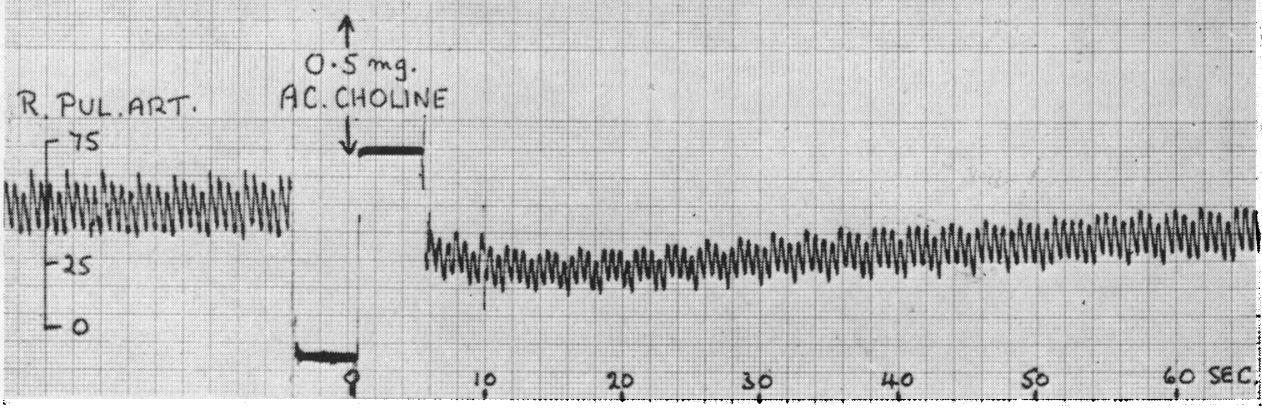

FIG. 7.-Case of aorto-pulmonary septal defect with the Eisenmenger reaction: there was moderate stenosis of the right pulmonary artery (A). Acetylcholine injected into the right pulmonary artery causes a sharp fall in pressure (B). 


\section{Obstructive Pulmonary Hypertension}

It has long been known that at least two-thirds of the total cross-section of the pulmonary vascular bed must be obstructed before the pulmonary blood pressure rises (Haggart and Walker, 1923; Gibbon et al., 1932). The commonest cause is massive, multiple or recurrent thromboembolism, and cases may run an acute, subacute, or chronic course. A thrombo-obstructive factor may also complicate any other form of pulmonary hypertension or pulmonary vascular disease.

Omitting acute cases of massive embolism, there were eight examples of subacute or chronic thrombo-embolic obstructive pulmonary hypertension in the present series. Apart from the characteristic history of phlebo-thrombosis preceding the onset, these cases presented like primary pulmonary hypertension, and if treated too late ran a similar course. Owen et al. (1953) described twelve typical cases.

The disease has been reproduced in animals by injecting finely fragmented fibrin clot intravenously into rabbits (Harrison, 1948). After lodging in and obstructing small pulmonary arteries, the clots gradually became organized, the lumina of the vessels became reconstituted, and marked fibroelastic intimal thickening resulted. The end product was similar to the findings in primary pulmonary hypertension.

Successful treatment depends upon early recognition, long-term anticoagulant therapy, the administration of pulmonary vaso-dilating agents such as priscol, aminophylline, and perhaps reserpine, and a prolonged attempt to keep the pulmonary blood flow as low as possible by means of rest, dehydration, and perhaps ganglionic blocking agents (to lower the venous filling pressure). The object is to keep the pulmonary blood pressure as low as possible while the pulmonary circulation is being restored, in order to prevent secondary vasoconstrictive or obliterative vascular reactions. One of my cases that seemed beyond redemption has been cured by these means, and another has been much improved, although her pulmonary vascular resistance is still moderately raised ( 6 units). Acetylcholine has not been given so far to any member of this group, so we are unable to state whether there is a vasoconstrictive reaction or not.

\section{Obliterative Pulmonary Hypertension}

Widespread occlusive pulmonary vascular disease has been demonstrated repeatedly both microscopically and by radio-opaque injection methods (Short, 1957) in practically all varieties of longstanding pulmonary hypertension. As explained previously, the most likely interpretation of these findings is that they represent an anatomical reaction to prolonged stress; that they are the result rather than the cause of pulmonary hypertension. When sufficiently severe and widespread, however, there can be little doubt that they increase the resistance still further, and accelerate the down-hill course of the disease.

The most notable and best-studied example of this secondary obliterative process is that already described in the later stages of Eisenmenger's syndrome. The consistently negative response to acetylcholine in this group suggests that obliterative pulmonary vascular disease presents a solid anatomical obstruction to flow, which can no longer be influenced by vital processes. If this interpretation is correct, then the response to acetyl-choline provides a simple physiological test of the degree of such obstruction.

More or less primary obliterative pulmonary hypertension may conceivably occur in schistosomiasis, disseminated lupus, and periarteritis, but few vital physiological facts are available in these cases.

\section{Pulmonary Hypertension in Cor Pulmonale}

It is difficult to know how best to classify pulmonary hypertension in cor pulmonale, because so often it appears to be polygenic, being brought about by a combination of obliterative, hyperkinetic, and hypoxic vasoconstrictive factors. 
There were 65 cases of well established cor pulmonale in the present series, and the pulmonary vascular resistance was raised, averaging 6.6 units, in 85 per cent of them; but the range was enormous, the resistance being normal ( 0.5 to 2 units) in 15 per cent, slightly raised ( 3 to 5 units) in 45 per cent, moderately raised ( 6 to 10 units) in 20 per cent, and extreme (over 10 units) in 20 per cent.

Hyperkinetic Factor. This was first demonstrated by Howarth et al. (1947), and was regarded as a compensation for hypoxia. In the present series, however, the average cardiac output was only 6 litres a minute at rest, and was very rarely above 10 litres a minute even when the resistance was low; these figures are well within the normal range for our laboratories. Since the patients with the highest pressures usually had the highest resistances and the lowest cardiac outputs, the hyperkinetic factor cannot be an important component of pulmonary hypertension in cor pulmonale.

Hypoxic Vasoconstriction. During acute infections transient alveolar hypoxia above the usual level increases the pulmonary hypertension in cases of emphysematous cor pulmonale by adding a vasoconstrictive factor, as described by Motley et al. (1947). It is not generally believed, however, that vasoconstriction initiated by alveolar hypoxia is maintained, for it cannot be demonstrated in chronic cases when free from infection and bronchospasm (Mounsey et al., 1952).

Obliterative Factor. Elimination of both the hyperkinetic and hypoxic factors as important causes of severe pulmonary hypertension in cor pulmonale appears to leave little choice but to assume that obliterative pulmonary vascular disease is responsible. The idea that more than two-thirds of the pulmonary capillaries were obliterated in emphysema has never had much appeal, but obliteration of capillaries, arterioles, and small muscular arteries from diffuse interstitial fibrosis could well be on the grand scale.

Acetylcholine Studies. Only four cases of cor pulmonale were given acetylcholine, and each was different.

A woman with mixed emphysema and fibrosis caused by extensive old pulmonary tuberculosis responded briskly, her P.A. pressure falling immediately from $87 / 32$ to $77 / 25$, the systemic blood pressure rising from $122 / 75$ to $130 / 80$, and the cardiac output rising from $3 \cdot 1$ to $3 \cdot 5$ litres a minute.

A man with the Hamman-Rich syndrome and a pulmonary blood pressure of $60 / 22$ responded briskly and in slightly greater degree; simultaneously his arterial oxygen saturation fell.

A man with diffuse interstitial fibrosis from sarcoid, a cardiac output of 6.7 litres a minute, P.A.P. 40/20, resistance 4 units, and arterial oxygen saturation 88 per cent, failed to respond in any way to $1.5 \mathrm{mg}$. acetylcholine.

A man with hypoxic cor pulmonale from emphysema, with a cardiac output of 3.5 litres a minute, P.A.P. 22/10, resistance 5 units, and arterial oxygen saturation 88 per cent, responded to acetylcholine by dropping his P.A.P. by $2-3 \mathrm{~mm}$. $\mathrm{Hg}$ and his arterial oxygen saturation by about 4 per cent.

Further work must be done before any firm conclusions can be drawn, but it is clear that a vasoconstrictive factor is commonly active in a variety of forms of chronic cor pulmonale, that it may particularly involve vascular pathways through poorly ventilated lung, and that diffuse interstitial fibrosis of at least one kind (sarcoid), may cause purely obliterative pulmonary hypertension in which no vasoconstriction can be demonstrated.

\section{Primary Pulmonary Hypertension}

The present series included 26 cases of primary pulmonary hypertension, 21 of them being female, between the ages of 9 and 48. The diagnosis has already been confirmed at necropsy in 17 of them, and so far there have been no diagnostic errors one way or the other. The clinical and pathological picture of this obscure disease has been described too often, and there is no point in belabouring it further. What is needed is more evidence concerning possible ætiological agents, and more light on early physiological behaviour.

Very suggestive is the work of Barnard (1954), who produced a form of intimal endarteritis fibrosa in mice and rabbits by injecting thrombo-plastin intravenously, so that fibrin emboli were 
formed in vivo. The end results of these experiments were virtually indistinguishable from those of primary pulmonary hypertension in man.

There can be no doubt that chronic thrombo-embolic pulmonary hypertension imitates primary pulmonary hypertension very closely, apart from the history of initial phlebo-thrombosis. But there are two differences that must not be ignored. Of my 8 severe and unquestionable thromboembolic cases imitating primary pulmonary hypertension, 5 were men, despite the female sex bias given to this condition by phlebo-thrombosis complicating pregnancy, as in the well-documented case described by Castleman and Bland (1946). Secondly, primary pulmonary hypertension may begin in childhood, as in 3 of my 26 cases: if these are thrombo-embolic the intravascular clotting must be of a very unusual kind.

Acetylcholine Studies. Six cases of primary pulmonary hypertension were given acetylcholine. A profound fall of pulmonary blood pressure (averaging $30 \mathrm{~mm}$. $\mathrm{Hg}$ systolic) and resistance was recorded in five of them; simultaneously the systemic blood pressure and cardiac output rose (Fig. 8). The magnitude of the response was unsurpassed in any other condition. There can be no doubt, therefore, that a powerful vasoconstrictor factor is commonly present in these cases, which at once distinguishes them from members of the Eisenmenger group. Since two of them had had the condition for 8 and 4 years respectively, long enough for secondary obliterative changes to have

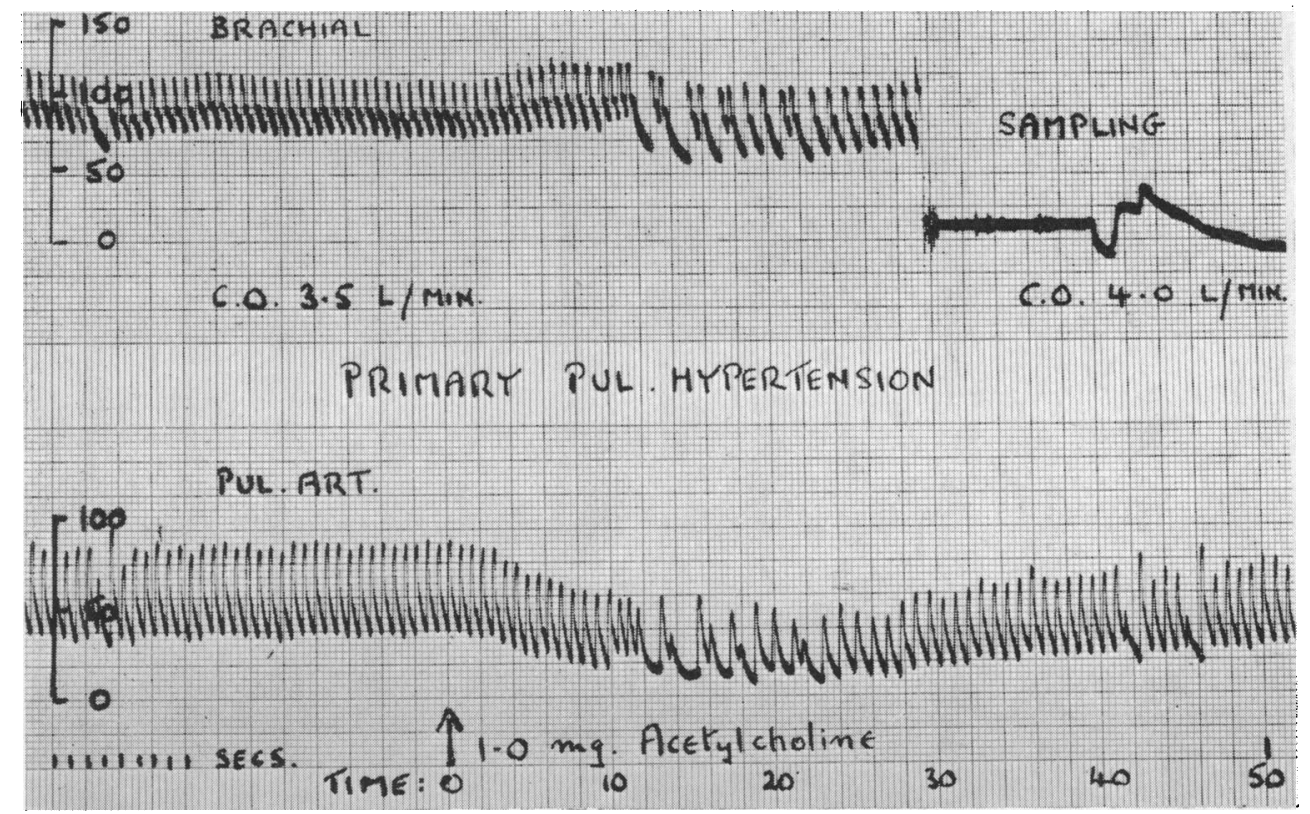

Fig. 8.-Effect of acetylcholine in a case of primary pulmonary hypertension.

developed, this difference in behaviour is all the more remarkable, and may well prove of fundamental significance.

In two cases of primary pulmonary hypertension the vasoconstriction was also relieved by aminophylline and priscoline, as demonstrated by Dresdale (1951). Therapeutically, however, these drugs proved valueless.

\section{SumMARY AND CONCLUSIONS}

A working classification of pulmonary hypertension is offered.

The mechanism of the chief varieties of pulmonary hypertension is discussed.

Acetylcholine has proved to be an excellent selective pulmonary vasodilator, and a useful tool with which to probe all forms of pulmonary hypertension in order to determine the degree of 
physiological vasoconstriction present. A maximum response includes a fall in pulmonary blood pressure and pulmonary vascular resistance, a rise in left atrial pressure (in mitral stenosis), cardiac output, and systemic blood pressure, and a fall in arterial oxygen saturation (especially in cor pulmonale).

The results are summarized in the Table and show that active vasoconstriction is strongest in primary pulmonary hypertension and in reactive pulmonary hypertension from mitral stenosis; it is present in some degree, however, in almost all forms of pulmonary hypertension except the Eisenmenger syndrome, in which it is consistently absent-at any rate in children over 5 years old.

The cause of the vasoconstriction has not yet been proved, but it is again suggested that it may well be a reaction to a high pulmonary blood pressure itself. However pulmonary hypertension is initiated, reactive vasoconstriction seems to aggravate and maintain it, and so closes a vicious circle.

Obliterative pulmonary vascular disease seems to develop gradually over the years in all forms of pulmonary hypertension, and also serves to aggravate and maintain the high resistance. Secondary thrombo-obstructive lesions develop later still.

The absence of demonstrable vasoconstriction in the Eisenmenger group may be due to secondary obliterative pulmonary vascular disease or possibly to an abnormal physiological response to acetylcholine on the part of vessels having fœtal characteristics. No information is yet available concerning the effect of acetylcholine on the pulmonary vascular resistance of infants under two years of age with the Eisenmenger syndrome.

\section{REFERENCES}

Adams, F. H., Lind, J., and Rauramo, L. (1957). Abstracts of Papers 30th Sc. Sessions of Amer. Heart Ass., Oct. 25-28. Chicago.

Barnard, P. J. (1954). Brit. Heart J., 16, 93.

Castleman, B., and Bland, E. F. (1946). Arch. Path., 42, 581.

Civin, W. H., and Edwards, J. E. (1950). Circulation, 2, 545. (1951). Arch. Path., 51, 192.

Cournand, A. (1950). Circulation, 2, 641.

Dresdale, D. T., Schultz, M., and Michtom, R. J. (1951). Amer. J. Med., 11, 686. (1947). Amer. J. Physiol., 150, 315.

Edwards, J. E. (1950). Proc. Inst. Med., Chicago, 18, 134. (1957). Circulation, 15, 164.

Gibbon, J. H., Hopkinson, M., and Churchill, E. D. (1932). J. clin. Invest., 11, 543.

Gilmour, J. R., and Evans, W. (1946). J. Path. Bact., 58, 687.

Haggart, G. E., and Walker, A. M. (1923). Arch. Surg., 6, 764.

Harrison, C. V. (1948). J. Path. Bact., 60, 289.

Hayward, G. W. (1955). Brit. med. J., 1, 1361.

Hickam, J. B., and Cargill, W. H. (1948). J. clin. Invest., 27, 10.

Howarth, S., McMichael, J., and Sharpey-Schafer, E. P. (1947). Clin. Sci., 6, 187.

Liljestrand, G. (1948). Arch. intern. Med., 81, 162.

Motley, H. L., Cournand, A., Werko, L., Himmelstein, A., and Dresdale, D. (1947). Amer. J. Physiol., $150,315$.

Mounsey, J. P. D., Ritzman, L. W., Selverstone, N. J., Briscoe, W. A., and McLemore, G. A. (1952). Brit. Heart J., 14, 153 .

Owen, W. R., Thomas, W. A., Castleman, B., and Bland, F. (1953). New England J. Med., 249, 919.

Short, D. S. (1957). Lancet, $2,12$.

Wood, P. (1956). Diseases of the Heart and Circulation. 2nd ed., Eyre \& Spottiswoode, London.

—, Besterman, E. M., Towers, M. K., and Mcllroy, M. B. (1957). Brit. Heart J., 19, 279. 